\title{
MULTICRITERIA DECISION-MAKING SOFTWARE APPLICATION IN HEALTH INFORMATION SYSTEMS RANKING: E-HEALTH PERSPECTIVE
}

\author{
Žarko Rađenović 29 \\ Ivana Marjanović ${ }^{30}$ \\ Ivana Zdravković ${ }^{31}$
}

https://doi.org/10.31410/itema.2018.82

\begin{abstract}
Health information systems represent a kind of information-technology platform for the electronic business of health organizations. By using health information systems, health organizations more effectively allocate their medical resources. By transferring real-time health information and diagnosing the condition of patients using virtual medical communities and mobile wireless body area networks, it comes all stakeholders networking of the healthcare organizations in charge of monitoring the health status of patients. All this leads to the creation of special kind of healthcare organizations electronic business, which is electronic healthcare. In order to reduce the costs of allocating medical resources, logistical costs and improving the provision of virtual medical services, each healthcare organization should choose an optimal health information system that matches its size, business mode and needs. Consequently, using the method of analytical hierarchical processes, through Bubble Chart Pro multi-criteria decision making software, health information systems in this paper will be ranked according to their most significant performance related to electronic health.
\end{abstract}

Keywords: $e$-health, health organizations, health information systems

\section{INTRODUCTION}

7 he task of selecting an optimal information system has become, in modern conditions, very complex for several reasons. First of all, it is difficult to adequately assess which information system is optimal since there are many different information systems on the market. Furthermore, there may be a problem of mismatch between the existing hardware and the desired software solution. Also, the lack of technical knowledge and experience of decisionmakers can present a problem. Another problem faced by decision-makers in modern conditions, when it comes to selecting an information system, is the rapid advancement of information technology.

The field of evaluation and selection of the information system has become the subject of many researchers' interests, since the process of selecting an adequate information system, that meets the specific needs of the institutions, is a complicated and time-consuming task, given the need to meet several criteria. Also, the choice will be different depending on the angle of view of the decision-makers, since not all interested users have the same goals (doctors are primarily interested in selecting a user-friendly system, nurses are interested in systems that allow easy entry and manipulation of data, economists want that the installed system will quickly recover

\footnotetext{
${ }^{29}$ Innovation Center, University of Niš, Jovana Skerlića 20A/28, 18000 Niš, Serbia

${ }^{30}$ Faculty of Economics, University of Niš, Trg kralja Aleksandra Ujedinitelja 11, 18000 Niš, Serbia

${ }^{31}$ Faculty for Entrepreneurial Business, University of Belgrade, Serbia
} 
the return of invested funds, while information experts are interested in the software tools of the system for supporting the electronic business of health organizations).

Choosing the wrong information system can not only represent an unjustified expense, but also negatively affect the business processes and functioning of the institution itself. Therefore, the main goal of this paper is to present one of the ways to evaluate health information systems using multi-criteria decision-making methods. Multi-criteria decision-making is the solution to the problem of choosing one of the more offered alternatives that are evaluated using multiple criteria's. Evaluation and selection of the information system can be considered as a problem of multi-criteria decision making, so multi-criteria methods can be used to solve them.

\section{METHODOLOGY}

Many methods for solving multi-criteria decision-making require clearly defined and expressed weight coefficients. Weight coefficients represent the importance of each attribute, that is, the contribution of each of the attributes to achieving the final goal. Therefore, assessment and assignment of weight coefficients plays a key role in the process of multi-criteria decision making and varies from decision-maker to decision-maker.

Weight coefficients should be consistent with the purpose of the analysis. Also, the weight coefficients themselves are useful information for those who are valorizing the solution of a specific problem solved by the methods of multi-criteria decision making, since they quantitatively show the preferences of the decision-maker.

Namely, the AHP method is used for multi-criteria analysis and making "correct" decisions in situations where it is necessary to decompose the problem into hierarchical sub-problems, and then analyze them independently of each other. [4] By determining the value and relative significance, based on the fundamental and primarily rational structured mathematical model, the potential alternatives are assigned the relative ability to solve the given problem, i.e. the desired goal of decision-making. Thus, the AHP method can usually be implemented: [6]

- Selection - selecting one alternative from a given set of alternatives based on the proposed criteria;

- Ranking - hierarchical setting of alternatives in relation to some reference and potentially expected alternative;

- Prioritization - defining the relative value of all parts of individual alternatives versus their ranking as a whole.

Weight coefficients should be consistent with the purpose of the analysis. Also, the weight coefficients themselves are useful information for those who are valorizing the solution of a specific problem solved by the methods of multi-criteria decision making, since they quantitatively show the preferences of the decision-maker. After searching the relevant literature and based on the knowledge and experience in this field, during the research, a set of criteria was selected, with the note that the subjectivity of the author is a limiting circumstance. During the survey, according to AHP (Analytical Hierarchical Process-Analytical Hierarchy Processes) and the software based on it Bubble Chart Pro, the following criteria for choosing the optimal electronic health software were used: [3]

- $\mathrm{C} 1$ - market share of e-health software (in\%);

- C2 - total number of software users;

- C3 - total number of patients who can be processed;

- C4 - monthly maintenance fee (in Euros); 
- C5 - the size of a health organization measured by the number of employees;

- C6- adoption rate: the rate of adoption of a software solution for e-health in a health organization (in \%) - the weighted average of average grades (1-9) of the basic characteristics of software solutions for electronic health divided by the number of them and multiplied by the number 100.

- C7- Combined score: ranking software based on the total user rating for the following features (1-9): user-friendly, interface, satisfaction, comprehensibility, information exchange. ${ }^{32}$

Bearing in mind the fact that the subject of the evaluation of the health information system through a review of literature related to information systems, the application of the AHP method can be found in numerous works. The method of analytical hierarchical processes (AHP) was developed by Saaty in the early seventies of the last century. AHP is a tool in decision analysis, designed to help decision-makers in solving complex problems involving a large number of decision-makers as well as a number of criteria.

The AHP method rests on a well-defined mathematical structure that allows the determination of own vectors on the basis of which the exact or relatively accurate weight coefficients are generated. The method of analytical hierarchical processes compares the criteria, or alternatives taking into account the criteria, by couples. In addition, a checked numerical scale is used that represents individual preferences taking into account quantitative and qualitative attributes. In this way, individual preferences are transformed into a scale of relationships.

The essence of the method is to structure a complex decision-making problem that can contain multiple criteria, multiple alternatives, as well as a greater number of decision-makers at several hierarchical levels, determining the weight coefficients of the criteria and alternatives by levels, and thus forming the final order of the alternative. The modeling process requires four phases:

- Creating a hierarchical structure, that is, determining alternatives, criteria, and subcriterion,

- Data collection using even comparisons to create a decision matrix,

- Estimating relative weights,

- Make a final decision.

The first phase involves explaining the problem of decision making. The problem is viewed as a hierarchy where the goal of the observed problem is at the top, while at lower levels there are criteria and possibly sub-criterion, depending on the complexity. At the lowest hierarchical levels, there are a number of alternatives that need to be evaluated.

The second phase of the AHP method involves data collection and comparison of pairs of hierarchical structure, both at a given level of hierarchy, and in relation to the criterion of a directly higher level. The essence of the pairing is to determine the preferences that the decision maker expresses to help Saaty's scale of relationship with 9 departments - Table 1.

\footnotetext{
${ }^{32}$ The value of this criterion was obtained on the basis of the conducted survey in the health centers of Niš and Leskovac, the Ministry of Health of the Republic of Serbia, while the values of this criterion for other health information systems were downloaded from http://www.capterra.com/electronic-medical-records-software/ \#infographic, accessed 12.06.2017.
} 
Table 1: Saaty's scale

\begin{tabular}{|c|c|}
\hline Scales & Degrees of preference \\
\hline $\mathbf{1}$ & Equally \\
\hline $\mathbf{3}$ & Moderately \\
\hline $\mathbf{5}$ & Strongly \\
\hline $\mathbf{7}$ & Very strongly \\
\hline $\mathbf{9}$ & Extremely \\
\hline $\mathbf{2 , 4 , 6 , 8}$ & $\begin{array}{c}\text { Intermediate values between which represent compromise } \\
\text { between previous values of importance }\end{array}$ \\
\hline
\end{tabular}

After completing this process, an appropriate matrix of comparisons is obtained which starts the third phase of the AHP method. The third phase of the AHP method consists in estimating relative weights. The comparison of pairs from the second phase results in a reciprocal $\mathrm{n} \times \mathrm{n}$ matrix A, where the elements are on the main diagonal, and the elements are calculated as the reciprocal values of the elements, that is, $\mathrm{i}, \mathrm{j}=1,2, \ldots, \mathrm{n}$. As a result of this comparison, in the fourth phase, at the level of the criterion, the relative significance of each criterion can be determined, expressed through a weight coefficient. On the other hand, at the level of alternatives it is possible to determine the ranking of alternatives for each of the observed criteria, both partially and collectively.

\subsection{BUBBLE CHART PRO: MULTICRITERIA DECISION- MAKING SOFTWARE}

Bubble Chart Pro combines the power of colorful bubble charts with powerful business analytics so that it can prioritizes, optimizes, and visualizes project portfolio data. This multicriteria decision-making software was designed to help managers make faster and better decisions in doing business. Bubble Chart Pro let managers quickly compare the relationships between business / project in critical business parameters such as cost, profit, and risk based on Analytic hierarchy process method. Thus, by visualizing project or business portfolios using Bubble Chart Pro ${ }^{\mathrm{TM}}$, managers can find clusters of relatively attractive projects in one area of the graph, such as areas of high value, low cost, and/or low risk, and compare them with relatively less attractive projects in a different area of the graph, such as an area of low value, high cost, and/or high risk. [2]

Bubble Chart Pro also includes a SMART project prioritization system for ranking projects and an easy-to-use optimizer for selecting best set of projects against multiple constraints such as limited capital, resources, time, and risk. The SMART (Simple Multi-Attribute Ranking Technique) project prioritization system that was developed to prioritize projects in a way that integrates all your key project data into a single value score so that it is understandable, robust, and rigorously defensible.

\section{DISCUSSION AND RESULTS}

In this paper, the AHP method will be used to determine the weight coefficients. In this case, the ideal solution is the point at which the utility for the decision maker is greatest, that is, the point in which the income attributes have the highest value, while the exponential attributes have the lowest value at the same time. Analytic hierarchy process (AHP) serves to solve complex problems such as choosing an optimal electronic health software alternative. [5] 
Considering the conflicting nature of the goals that economic decision makers face, it is necessary to compare the alternatives in order to choose the optimal one. The AHP method is based on determining the relative importance of the selected criteria, or allocating relative weights using matrices. By using the Bubble Chart Pro software, it is possible to evaluate attribute and hierarchical representation of alternatives based on their mutual relationship. Using the relevant data (Table 2), the criteria are prioritized using the Saaty scale.

Table 2: Values of criterions for each electronic health software solution

\begin{tabular}{|c|c|c|c|c|c|c|c|}
\hline \multirow{2}{*}{$\begin{array}{c}\text { Software for health } \\
\text { information systems }\end{array}$} & $\mathbf{C}_{\mathbf{1}}$ & $\mathbf{C} \mathbf{C}_{\mathbf{2}}$ & $\mathbf{C}_{\mathbf{3}}$ & $\mathbf{C}_{\mathbf{4}}$ & $\mathbf{\mathbf { C } _ { 5 }}$ & $\mathbf{C}_{\mathbf{6}}$ & $\mathbf{C}_{\mathbf{7}}$ \\
\cline { 2 - 10 } & $10,3 \%$ & 850.000 & 115.000 & 250 & 50 & $3 \%$ & 2,5 \\
\hline eClinicalWorks & $1,1 \%$ & 200.000 & 40.000 & 100 & 50 & $3 \%$ & 2,6 \\
\hline McKesson & $3,1 \%$ & 232.623 & 47.186 & 295 & 30 & $4 \%$ & 4 \\
\hline CureMD & $1,9 \%$ & 112.000 & 30.000 & 1 & 30 & $8 \%$ & 3,83 \\
\hline Practice Fusion & $6,5 \%$ & 180.000 & 10.000 & 1 & 20 & $6 \%$ & 2,83 \\
\hline All Scripts & $8,2 \%$ & 150 & 150 & 66 & $3 \%$ & 7,26 \\
\hline Heliant Health & $0,001 \%$ & 20.000 & 5.160 & & & & \\
\hline
\end{tabular}

By entering the decision matrix data, the corresponding model, as well as the relative weight of each criterion, is defined for individual software solutions for electronic health (Table 3), after their mutual comparison according to given criteria.

Table 3: Weight coefficients for all analyzed electronic health softwares in this paper according to AHP

\begin{tabular}{|c|c|c|c|c|c|c|c|}
\hline \multirow{2}{*}{$\begin{array}{c}\text { Software for health information } \\
\text { systems }\end{array}$} & \multicolumn{7}{|c|}{ Weighted coefficients for each criterion for software } \\
\cline { 2 - 9 } & $\mathbf{C}_{1}$ & $\mathbf{C}_{2}$ & $\mathbf{C}_{\mathbf{3}}$ & $\mathbf{C}_{4}$ & $\mathbf{C}_{\mathbf{5}}$ & $\mathbf{C}_{\mathbf{6}}$ & $\mathbf{C}_{\mathbf{7}}$ \\
\hline eClinicalWorks & 1,00 & 1,00 & 1,00 & 0,68 & 1,00 & 0,39 & 0,28 \\
\hline McKesson & 0,13 & 0,25 & 0,28 & 0,67 & 1,00 & 0,39 & 0,35 \\
\hline CureMD & 0,07 & 0,33 & 0,36 & 1,00 & 0,39 & 0,46 & 0,78 \\
\hline Practice Fusion & 0,29 & 0,09 & 0,13 & 0,27 & 0,39 & 1,00 & 1,00 \\
\hline All Scripts & 0,48 & 0,16 & 0,06 & 0,28 & 0,26 & 0,99 & 0,95 \\
\hline Heliant Health & 0,51 & 0,48 & 0,07 & 0,65 & 0,88 & 0,50 & 0,69 \\
\hline
\end{tabular}

For each of the criteria given in Table 3, Bubble Chart Pro calculated their relative weight and prioritized them. Based on the budget, it is seen that the combined rate $(\mathrm{C} 7)$ criterion has the highest priority in selecting an optimal software alternative, with a value of 0.411 . It is important to emphasize that for analytical hierarchical processes, the validity of the model is assessed on the basis of an index of inconsistency, the value of which should not exceed 0.1 . Based on Fig. 1, it can be seen that the value of the index of inconsistency for the observed 
model is 0.1 , which indicates the correct choice of criteria and their mutual relationship according to Saaty's scale with respect to the law of transitivity ( $\mathrm{a}>\mathrm{b}$ and $\mathrm{b}>\mathrm{c}$ then and $\mathrm{a}>\mathrm{c}){ }^{33}$

Figure 1: Bubble Chart Pro calculated weights for electronic health software alternatives

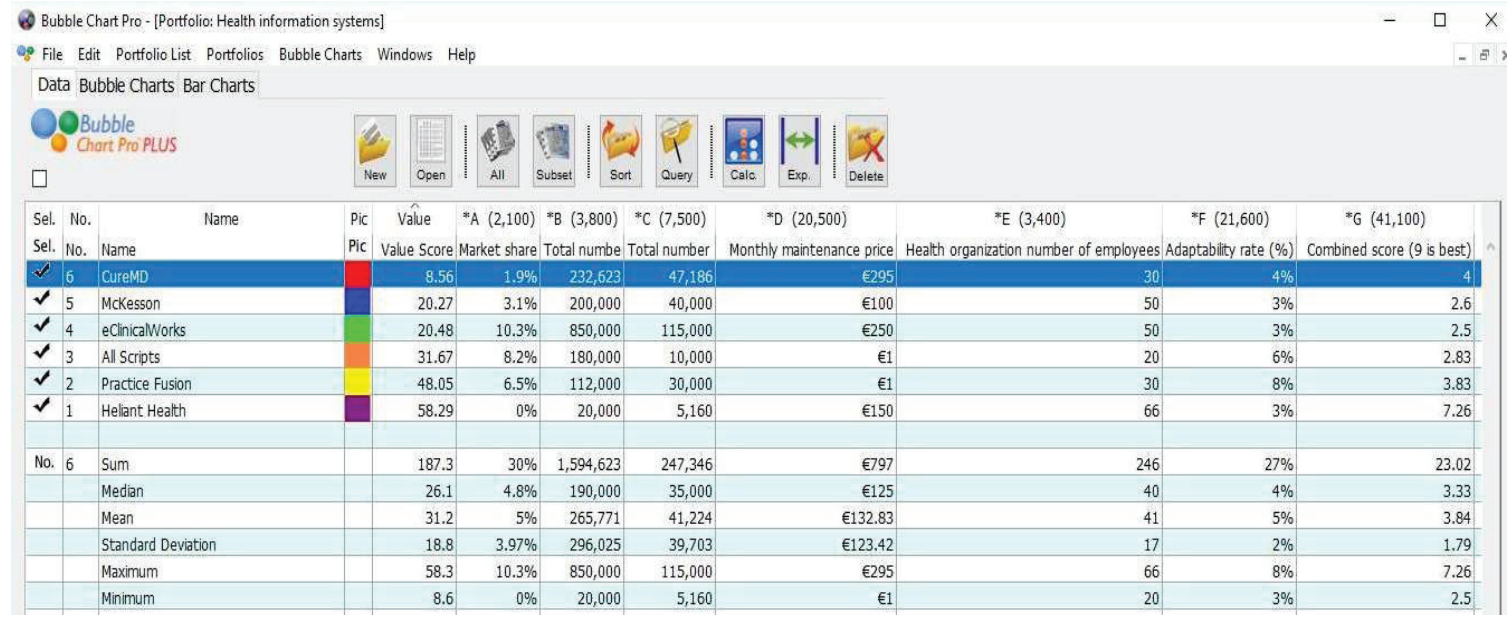

In order to choose the optimal alternative of electronic health software solutions Bubble Chart Pro has created bubble graphs in three dimensions, which show us the actual relationship of above mentioned group of analyzed softwares. Namely, on the Figure 2 we could see relationships of those softwares using criteria's such as market share and combined score, which are analyzed in context of Overall Value Score (OVS) as third dimension. In this view of mentioned bubble chart, chart area is bounded by the highest and lowest electronic health software criteria values and divided in four quadrants. This allows us to identify the most attractive and the least attractive areas. In this chart, as the most attractive area for market share criteria is the fourth quadrant, where eClinicalWorks has the best value (green bubble), but the most attractive area for the combined score criteria is the second quadrant (upper left), where Heliant Health has the best position on this chart (violet bubble).

Figure 2: Relationships of electronic health softwares using criteria's such as market share and combined score

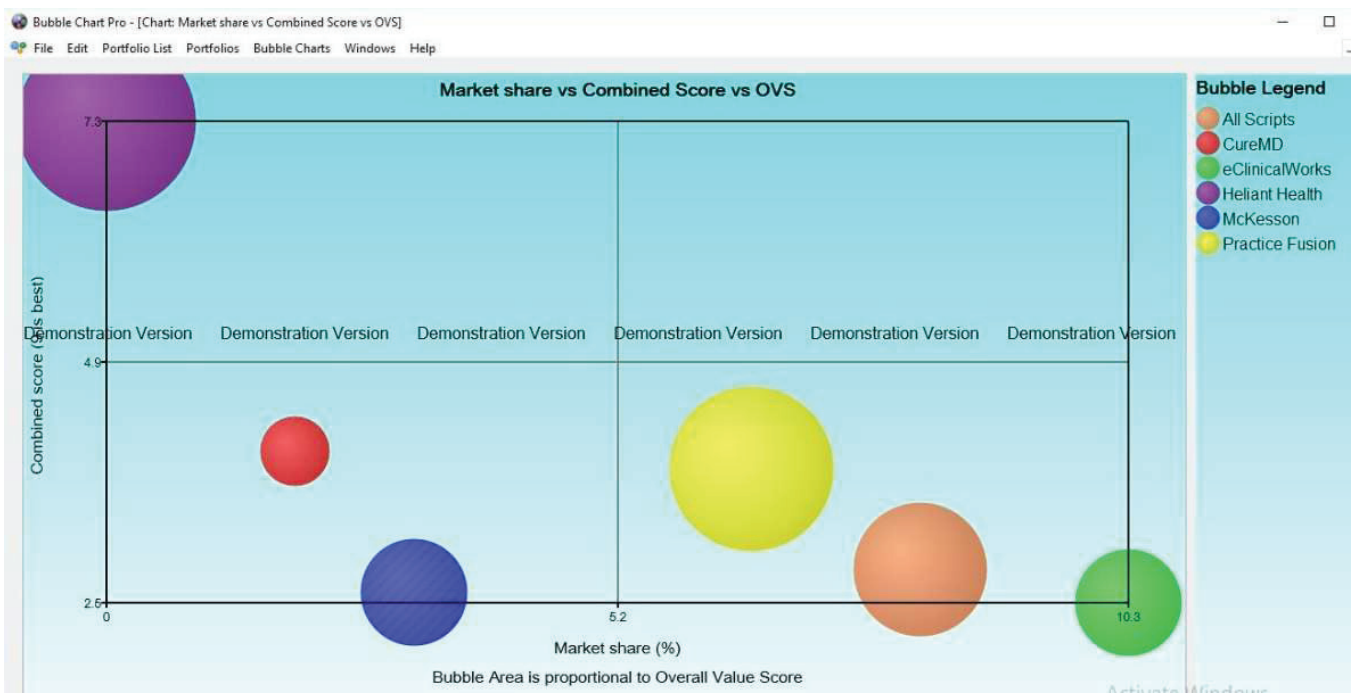

\footnotetext{
${ }^{33}$ According to consistency index formula: $\mathrm{CI}=(\kappa \max -n) /(n-1)$, where $K \max$ represents the average value of weighted coefficients sum of criterions divided by their number
} 
On the Figure 3, as the most attractive area for market share criteria is the second (upper left) quadrant, where eClinicalWorks has the best value (green bubble), but the most attractive and optimal area for the adaptability rate criteria is the border between first and fourth (right down) quadrant, where Practice Fusion has the best position on this chart (yellow bubble).

Figure 3: Relationships of electronic health softwares using criteria's such as market share and adaptability rate

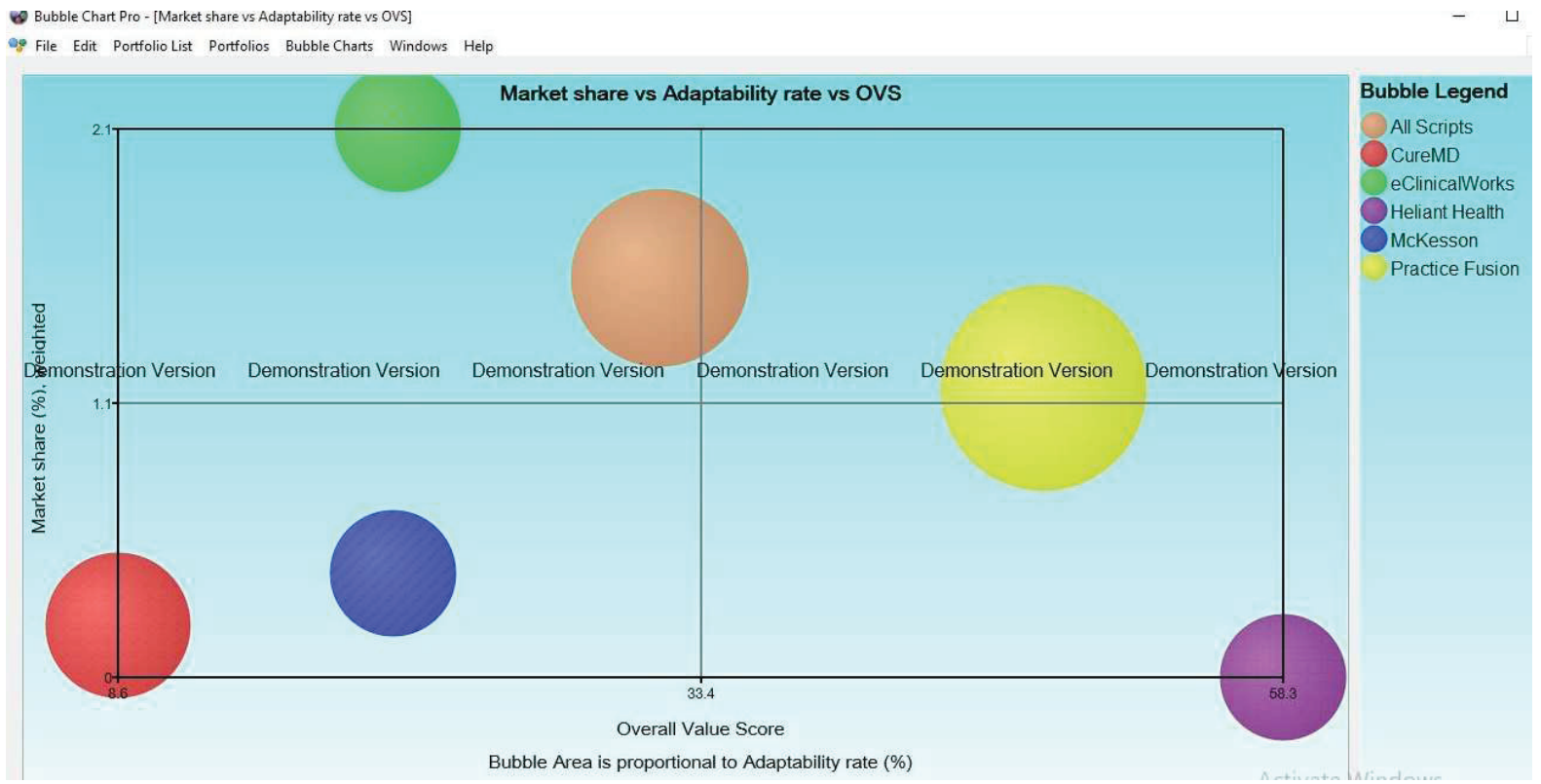

Dynamic attributes contribution, as a result of dynamic sensitivity analysis in Bubble Chart Pro, represents the percent of contribution for each criteria in the dynamic criteria structure of electronic health softwares. This graph (Figure 4) give decision makers more detailed structure of ranked softwares and more sensitivity, for choosing the optimal software alternative and therefore its implementation into the health organization information system:

- McKesson alternative has the significant percent contribution for the monthly maintenance price, and it is not the best and cost- effective solution.

- All Scripts has the well balanced contribution of criteria's such as adaptability rate and maintenance monthly price.

- CureMD alternative has the most significant contribution in combined score.

- eClinicalWorks has the most significant percentage contribution in total number of patient processing and stakeholders, and also has the best market share.

- Healiant Health has the best combined score contribution in the dynamic software structure, but very high price of maintenance.

- Practice Fusion has the best relationship between combined score and adaptability rate. 
Figure 4: Dynamic percentage contribution of each criterion in optimal electronic health software structure

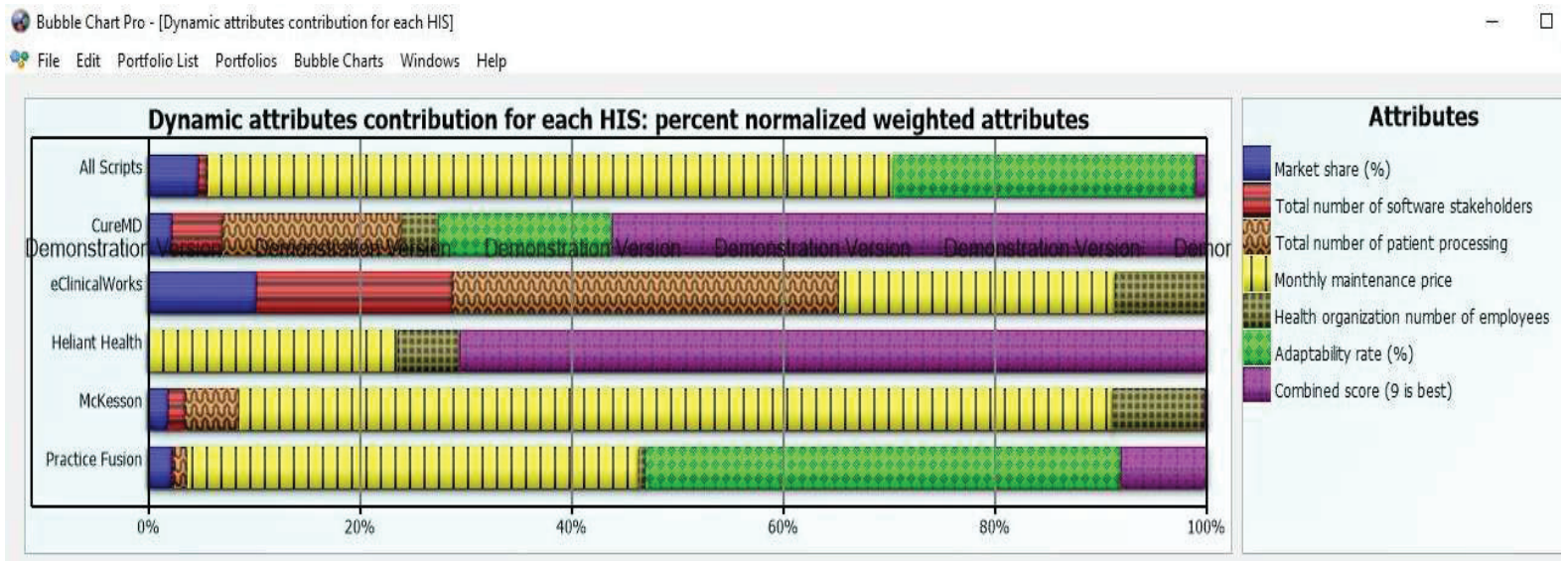

\section{CONCLUSION}

Health information systems and electronic health care as an integral part represent a major important information and technology opportunity for the health sector, which is facilitated by the rationalization of the costs of providing health services and improving the efficiency and quality of the complete healthcare system. Internet-based e-submission of healthcare organizations faces numerous challenges when spending optimization costs and raising the level of interoperability of healthcare organizations by using software solutions for health information systems. The evolution of health information systems is becoming a modernization of the provision of health services in real time, with shortening of time interventions and reducing the risk of negative outcomes.

Health information systems enable equal allocation of medical resources to the targeted priority population of patients, while striving for the rational exploitation capacity of health organizations. This refers primarily to the function of monitoring the flow of patients from the country of the health information system in order to avoid unnecessary endangering the capacity of the hospital users.

Because of those reasons, multi-criteria decision-making softwares play the significant role helping health organizations managers and medical stuff to make the optimal decision, especially in choosing the right electronic health software alternative. As we can see in analysis, the optimal electronic health softwares are those which have low price of maintenance, userfriendly interface, great scalability and low redundancy rate of medical data, which means the great combination of adaptability and combined score such as Practise Fusion software.

\section{REFERENCES}

1. http://www.capterra.com/electronic-medical-records-software/\#infographic,accessed accessed 12.11.2018.

2. https://download.cnet.com/Bubble-Chart-Pro-Optimal/3000-2076 4 75687328.html, accessed 29.11.2018

3. Kostić, Z., Rađenović, Ž. (2017) ANALIZA KONKURENCIJE ZDRAVSTVENIH INFORMACIONIH SISTEMA PRIMENOM SOFTVERA ZA VIŠEKRITERIJUMSKO ODLUČIVANJE, Info $\mathrm{M}$, Časopis za informacionu tehnologiju i multimedijalne tehnologije, Vol. 62/2017, ISSN 1451-4397, UDC 005:004:6 
4. Saaty, T. L. (1990). How to make a decision: the analytic hierarchy process. European Journal of Operational Research, 48 (1), 9-26.Saaty, T.L. (1980) The Analytic Hierarchy Process, New York: McGraw Hill.

5. Sheta,E.O. \& Eldeen, A.N. (2013) THE TECHNOLOGY OF USING A DATA WAREHOUSE TO SUPPORT DECISION- MAKING IN HEALTH CARE, International Journal of Database Management Systems, Vol.5,No.3, 75-85 str.

6. Wager, K.A., Lee, F.W. \& Glaser, J.P. (2017) Health Care Information Systems: A Practical Approach for Health Care Management, Published by Jossey-Bass, A Wiley Brand, San Francisco, 1-62 str. 